\title{
3 Consciousness, Culture, and Significance
}

\section{Christoph Durt}

This chapter offers a new view on the relation between consciousness and culture by investigating their intertwinement with significance. I argue that consciousness discloses aspects of significance, while culture encompasses shared significance, as well as the forms of behavior that enact significance. Significance is linguistic or nonlinguistic meaning that is (partly) understood in intersubjective engagement and constantly reinstantiated in new contexts of relevance rather than belonging to single individuals (cf. Gallagher, this vol.). Significance is embedded in the shared world to which we relate through cultural forms of thinking and sense-making.

As in other chapters, several of which will be taken up here, the discussion that follows is inspired by thoughts from Edmund Husserl, without relying on his terminology. Furthermore, it integrates studies from two authors who would otherwise be underrepresented in this book-Gilbert Ryle and Ludwig Wittgenstein—and considers the implications of their thoughts for contemporary discussions of consciousness and culture. In spite of the fundamental differences between these three authors, they provide complementary insights into how consciousness and cultural forms of behavior accomplish significance.

Consciousness and culture are often defined in ways that obscure their relation to significance. Consciousness tends to be reduced to a limited concept of experience, such as in the debates around "phenomenal consciousness." Reflective aspects of consciousness are construed by what Ryle calls "thin description" (Ryle [1968] 2009, 501). Culture, by contrast, tends to be defined in very thick terms at the expense of thinner forms of cultural behavior. I will explain this by reference to Clifford Geertz, who made thick description the defining characteristic of culture, and argue that this definition neglects the foundational role of "thinner" cultural behaviors.

Significance is accomplished in embodied processes. At a basic level, these processes include the forms of behavior shared by most or all humans. Behavior is to be understood not thinly as lacking significance but thickly as itself resting on different levels of significance. At higher levels, forms of behavior become more complex, as well as more specific to groups of people, and allow for more complex manifestations of significance. The forms of behavior common to some or all people are cultural; culture accomplishes significance. 
The claim that consciousness encompasses different levels of significance gives rise to the question of their connection. "Hybrid" concepts of cognition propose that there are two distinct parts of the mind, such as a motor-perceptual and a reflective part. Di Paolo and De Jaegher (this vol.) worry that hybrid concepts of cognition perpetuate dualism by seeing only "direct action-based mechanisms" as embodied and those involved in "more reflective tasks" as disembodied. Here I argue, with regard to Merlin Donald's concept of the "hybrid mind" (Donald 2001, 164), that the underlying issue should not be framed in terms of embodied versus disembodied systems of production; even computers are in some sense "embodied." Rather, there is a categorical difference between different levels of significance. Embodied consciousness not only accomplishes but also integrates different levels of significance.

\section{Phenomenal and Reflective Consciousness and Significance}

This section takes its departure from standard definitions of consciousness as phenomenal experience and argues that they do not suffice to explain reflective forms of consciousness such as understanding and thinking. These acts accomplish forms of significance that need to be accounted for by "thick description" (Ryle [1967] 2009, 489). While definitions of consciousness in experiential terms attempt to describe consciousness rather thinly, much of consciousness involves thicker levels that cannot be reduced to thin description.

\subsection{Phenomenal and Reflective Consciousness}

Since the early modern formulations of the distinction between primary and secondary qualities, philosophers have tried to come to terms with the paradox caused by (1) the assumption that ideas of secondary qualities must be produced by primary qualities, and (2) the claim that we cannot even conceive how this is possible. In Locke's words, we "can by no means conceive how any size, figure, or motion of any particles, can possibly produce in us the idea of any colour, taste, or sound whatsoever; there is no conceivable connexion between the one and the other" (Locke [1689] 1836, 419; cf. Durt 2012, 2-3). Today the distinction between ideas of primary qualities and ideas of secondary qualities tends to be glossed over, ${ }^{1}$ and all are subsumed under the terms "phenomenal character," "phenomenal consciousness," "qualia," "phenomenal experience," or simply "experience." But the paradox lives on, now framed by the question of how experience can be accounted for by naturalism, a

1. The distinction is still implicitly at work in the tendency to define phenomenal character with reference to secondary rather than primary qualities, and it sometimes resurfaces explicitly, for example, in the claim that "we need qualia to make sense of secondary qualities" (Shoemaker 1990, 114). Understanding why ideas of primary qualities have traditionally not been seen as a challenge to a mechanistic account of the universe may be key to a more differentiated understanding of the challenge of "experience" to naturalism. 
question that is supposed to constitute "the hard problem of consciousness" (Chalmers 1995, 202). Here again, the study of consciousness continues to be driven not by the richness of conscious phenomena themselves but by the troubles some aspects of consciousness seem to provide for naturalism's attempt to explain everything there is.

That the use of "consciousness" is driven by theoretical purposes explains why its discussion in these contexts is limited to phenomenal consciousness, but it doesn't justify the limitation. Framing problems of consciousness in terms of "qualia" and "intentionality" has even been called "extremely ethnocentric," because "very few non-Western cultures would view the matter in the way that Western consciousness researchers might conceive of it" (Throop and Laughlin 2007, 633). The discrepancy with ordinary views of consciousness, however, also exists also in relation to "Western culture," for "consciousness" in ordinary English has a much wider sense than its technical uses in contemporary philosophy. The discrepancy by itself is, of course, not an argument against framing consciousness in technical terms, but it indicates that a better understanding of consciousness needs to go beyond the very narrow use of "consciousness" within some currents of Western philosophy. This chapter does so, not by denying phenomenal and intentional aspects of consciousness but by reinterpreting them from a wider point of view that shows that both go together with reflective consciousness.

The ordinary concept of consciousness includes the intransitive aspect of "being awake rather than asleep or otherwise unconscious" and the transitive aspect of "being conscious of something or other" (Hacker 2002, 157). Defining consciousness in terms of the phenomenal character of experience considerably extends the concept to include "the whole domain of 'experience' - of 'Life' subjectively understood" (157). On the other hand, such definitions restrict the concept of consciousness to a limited notion of experience and tend to leave out reflective understanding and highly reflective activities such as thinking. This omission is ironic, since reflective understanding and thinking are prime examples of activities of consciousness in the ordinary sense of the word. Of course, not all consciousness is highly reflective, and there may be unconscious activities that can be called "understanding" and "thinking," but usually these are performed in consciousness.

The relatively recent discussion of "cognitive phenomenology" brings to the fore the idea that phenomenal consciousness and cognitive accomplishments are inherently connected. ${ }^{2}$ Matthew Ratcliffe neatly summarizes the two basic questions of cognitive phenomenology as (1) whether "the phenomenal content of perception in one or more modalities incorporate[s] conceptual, propositional or other ingredients that are properly regarded as 'cognitive,'” and (2) whether "non-sensory cognitive states and processes have phenomenal content too, the focus being on 'thinking'" (Ratcliffe 2014, 355). Answering yes to either question would cast

2. Today the more common term is "achievement," which, however, carries the connotation of the completion of a difficult task or goal. Accomplishments are not necessarily difficult and do not need to involve goals. 
doubt on the strict distinction between phenomenal consciousness and cognitive states. To make real progress at this point, moreover, we need to go beyond the dichotomy between phenomenal content and intentionality and consider how experience and understanding come together in consciousness.

The classical definitions of phenomenal experience try to refer to it deictically in terms of "what it is like." Thomas Nagel (1974), for instance, takes the "what it is like" to be a member of a species as the necessary and sufficient condition of consciousness. Other instances are the "what it is like" of seeing a certain shade of red or understanding the sentence "two plus two is four" (Searle 2000, 561). Higher-order theories of consciousness make a similar move by supposing that there are higher-order "states" that are supposed to make lower-order mental "states" conscious. The higher-order states are again usually defined by a "what it is like" to be in the lower-order state (Rosenthal 2004, 29). In the same vein, Strawson's concept of "understanding experience" (Strawson [1994] 2010, 5) or "meaning-experience" (7) concerns the thin experiential difference between, for example, understanding a French sentence and merely hearing the words.

The concept of "understanding experience" is clearly not enough to explain the difference between understanding and not understanding, since to understand something, it does not suffice to have an experience that goes along with understanding; Strawson himself admits that one can have such an experience without understanding ([1994] 2010, 7). But is the experience of understanding enough to account for the difference between what goes on in consciousness when one understands a French sentence and when one doesn't understand the sentence? An affirmative answer presupposes that consciousness is merely experiential consciousness in a thin sense of experience.

Against such a definition, I hold that consciousness can also comprise understanding in a fuller sense. "Understanding" is not meant to be independent of experience or to be another thing in addition to experience. Rather, it is a "thicker" level of experience. In consciousness, understanding always goes along with experience; we do not understand with a pure intellect but do so with the help of perceptions and imaginations. Claiming that understanding is exhausted by associations between perceptions and imaginations is psychologism, a position that, in contrast to other forms of reductionism, is not particularly common today. Instead, understanding is typically conceived as inessential to consciousness itself, and consciousness is restricted to experiential contents in a thin sense. I think that this conception disregards something extremely important: by becoming conscious of a thing or relation, we understand something about it.

\subsection{Consciousness and Significance}

When we consciously experience or understand something, we become aware of part of its significance. With the concept of significance, I take up the distinction between meaning and significance, which has been used to interpret Hans-Georg Gadamer as holding that even "if there actually is an unchanging meaning that belongs to a text, there is no access to 
it that doesn't go by way of significance" (Gallagher, this vol.). I here do not, however, limit the concept to texts or even language. The crucial point is that significance is not bound to individual consciousness but shared between conscious beings and always newly reinstantiated. This is so because each individual act of consciousness reveals only a certain significance, which can be developed further in additional acts. In some cases, this may lead to modifications to which the author or speaker can object "that's not what I meant," but that too is an interpretation of what she meant; it doesn't imply that meaning is fixed in one act of rigid designation.

I contend that disclosing significance is an essential accomplishment of consciousness. Consciousness is usually "about" something or "intentionally directed" toward something, which may be a perception of an object or the understanding of a state of affairs. What consciousness becomes aware of in both cases is an aspect of the significance of the object or relation it is about. In consciousness we disclose aspects of the significance of the things and the relations of which we are conscious. Significance is not just content in the sense of "the way [an intentional state] represents what it is about or directed on" (Crane 2013, 5), but it discloses aspects of the objects and relations intended. The disclosing of significance in consciousness is an accomplishment of consciousness in the verbal sense, and the disclosed significance is an accomplishment in the nominal sense.

The term "significance" is here understood as comprising not only the conventional meaning of signs and symbols or the importance of something for human life but also sense and meaning more generally. The concept avoids the-in my view-misguided dichotomy between intension and reference that goes back to a particular interpretation of Gottlob Frege's distinction between sense (Sinn) and meaning (Bedeutung). This interpretation conceives of meaning (reference) as being in the world and sense (intension) as somewhere else-either in Frege's "third world" (drittes Reich; Frege [1918] 2003, 50) or, as probably most adherents of the dichotomy today think, in the mind. In contrast to this distinction, I conceive of significance as, on the one hand, accomplished by culturally shared ways of interacting with one's environment; significance is not detached from the world. On the other hand, significance is accomplished by consciousness; it is not detached from the mind. Nor is it a third thing in between mind and world. Rather, it is the way the world is given to us due to our ways of making sense of it. While significance is embedded in activity, it is-unlike sensemaking - not the activity itself; in the view presented here, sense-making is directed toward significance. Significance is accomplished by individuals in individual acts, but the accomplished significance is more than the accomplishing acts. Conceiving consciousness as disclosing significance thus stands radically opposed to purely intrinsic and solipsistic concepts of consciousness.

To say that consciousness discloses significance is not to say that consciousness discloses all at once the whole significance of what it is about. Rather, consciousness usually discloses only extremely limited parts of significance. In Husserl's expression, we only experience "adumbrations" (Abschattungen) of things. Analogously, in reflection we only understand certain aspects of the significance of things or relations. Consciousness is about things that 
are not all disclosed in a current state of consciousness or in any individual consciousness alone; it is open to features of the environment (McDowell [1994] 2002, 450). Significance concerns things and relations in the intersubjectively shared world, which Husserl also calls the "lifeworld" $(1962,48)$. Significance can reach into the sense-making of past and future generations, for example, through writing and inherited forms of interaction.

Those who know Husserl will readily recognize further connections to other key Husserlian concepts such as intentionality, noesis and noema, and accomplishment or achievement (Leistung). Husserl calls the accomplishing activity of "transcendental consciousness" in disclosing significance "constitution," and he uses this term to refer to, among other things, the constitution of objects by transcendental consciousness (cf. Husserl [1913] 1976, 344-359). A detailed study of the Husserlian terminology can contribute to sharpening the issues involved, but I will concentrate instead on bringing the previously outlined ideas together with insights from Ryle and Wittgenstein. ${ }^{3}$ While important differences exist between phenomenology and ordinary language philosophy, including the emphasis each puts on egological consciousness and intersubjective behavior, Dermot Moran rightly states that those who "overemphasize [Husserl's] focus on the individual life of intentional consciousness as reconstructed from within ... tend to overlook [his] original, radical, and fundamentally groundbreaking explorations of intersubjectivity, sociality, and the constitution of historical cultural life" (this vol., sec. 1). On the other hand, Ryle's and Wittgenstein's insights into significance and culture can complement the phenomenological study of consciousness, as I will show.

\section{Thinner and Thicker Descriptions of Consciousness}

This section reinterprets Ryle's distinction between thin and thick description of behavior as a distinction between levels of significance and considers how it can be applied to the concept of consciousness. Defining consciousness in terms of the phenomenal character of experience involves a relatively thin description of consciousness, and other activities of consciousness such as thinking require thicker descriptions.

\subsection{Thinner Description of Consciousness}

Ryle introduces the concept of "thick description" in his essay Thinking and Reflection (Ryle [1967] 2009, 489). He explains how it differs from "thin description" in The Thinking of Thoughts: What Is "Le Penseur" Doing? by way of example: "Two boys fairly swiftly contract the eyelids of their right eyes. In the first boy this is only an involuntary twitch; but the other is winking conspiratorially to an accomplice. At the lowest or the thinnest level of description the two contractions of the eyelids may be exactly alike" (Ryle [1968] 2009, 494). Thin

3. Another closely related author is Martin Heidegger, whose terminology I will not consider here. For a study on Heidegger in relation to language and significance, see Inkpin 2016. 
description alone does not allow us to distinguish between a twitch and a wink; it consists only of observations of bodily movements, and in Ryle's example, the twitch and the wink look exactly alike. To distinguish them, we need thick description.

The lowest level of description of the two boys' behavior is not the twitch. A twitch is not just a contraction of an eyelid but an involuntary contraction of an eyelid, which also means it is not a wink. Because involuntariness has to be included in the description of the twitch, the description of a contraction of an eyelid as a twitch is a thicker description than just the description of the contraction of an eyelid, which Ryle calls "thin description." The description of the wink is even more obviously thick because it includes the fact that the winker was deliberately signaling to "someone in particular, without the cognizance of others, a definite message according to an already understood code" ([1968] 2009, 494). Recognizing a twitch or a wink entails thin description, at least implicitly; it depends on recognizing the movement of the eyelid. But it adds another layer that cannot be accounted for by thin description. Yet further layers can be added: Ryle's examples are the parodist mocking a clumsy wink, and the parodist practicing his parody. The series of layers of meaning could be extended indefinitely.

Ryle's metaphor for thick description, with its hierarchical structure and extendibility, "is a many-layered sandwich, of which only the bottom slice is catered for by that thinnest description" ([1968] 2009, 497). Ryle's term "bottom slice" sounds as if he thought of thin description as a foundation on which higher levels of description would have to be added. But the foundation of a sandwich is not like the foundation of indubitable knowledge that Descartes expects from his "je pense, donc je suis" (Descartes [1637] 1902 [Discours], 32). A bottom slice is neither an unanalyzable given nor a core; it may be necessary for the whole, but it is not its essence. Furthermore, the different slices or layers constitute a whole; there is only one action, which can be described in both thin and thick terms. The thin description of the wink may be perfectly true and relevant; the problem is that it doesn't suffice to distinguish a wink from a twitch. "Thin description" is to be understood not as an origin, essence, or unquestionable foundation but as something that is implicit and part of any thicker description, regardless of how many layers it has.

The distinction between thin and thick description is very different from Ryle's famous distinction between knowing how and knowing that because it does not categorically distinguish between two mutually exclusive types. The border between thick and thin is imprecise: just as there are thinner and thicker people, and people who are somewhere in between, so there are descriptions that are thicker than the thinnest possible description, yet not thick. It is not always possible to draw a sharp boundary between both, but usually we can distinguish pretty well between thin and thick. In other words, the difference between thin and thick description is not absolute but relative; thick description is relative to the thinner levels it builds on.

Ryle's distinction between thin and thick description is not a distinction between something that is observable and something that cannot be observed; both the twitch and the 
wink are observable behavior. Rather, thin description is an incomplete description in that it includes neither the cause nor the significance of the behavior. The observed contraction of an eyelid is not just a contraction of an eyelid; it is either a twitch or a wink, or it may indicate something else entirely. We may never know the cause of a particular contraction of an eyelid, but it certainly has some cause. Ryle doesn't say whether a description that includes the physiological causes of the behavior is still a thin description, and I will consider this question in section 4.1. Yet it is clear that when we can determine that the contraction of an eyelid is due to the attempt to signal something, we are giving a thick description.

I interpret Ryle's distinction between thin and thick description as a distinction between levels of significance. Thin description of an action has significance in its own right and can be understood if the respective observational terms are understood. But it abstracts from the full significance of the respective action and is in this regard underdetermined. While Ryle applies his concept of thin description only to behavior, we can apply it also to definitions of consciousness in terms of the phenomenal character of experience. Such definitions are thin because they make no use of significance beyond the level of observation.

In the case of the phenomenal character of experience, the observation is alleged to be possible from a first- rather than a third-person perspective. Both kinds of observation abstract from the full significance of the objects or relations of which we are conscious. For instance, a color experience is always part of the visual field. It usually discloses one aspect of an object, which exists in relations to other objects. Usually we become immediately aware of higher levels of significance, such as the significance of a green traffic light in its context of an empty crossing. I here leave open the question of how far it is even possible to describe the phenomenal character of experience independently of further significance. Even if it is at all possible, the phenomenal character is not completely void of significance in at least a minimal sense, for otherwise it would have no determinate character that is directed toward objects or relations in the world. In either case, the description is at least as thin as the description of a contraction of an eyelid. Attempts to define consciousness in terms of the phenomenal character of experience are attempts to give a thin description of consciousness.

\subsection{Thicker Descriptions of Consciousness}

One may say that in simple observation there is already understanding, for example, of what a wink means. Yet consciousness also includes and produces much more reflective forms of understanding. A highly reflective form of consciousness is thinking, which is worth considering a little further. As an example of a thinker, Ryle asks us to consider Rodin's bronze sculpture Le Penseur, which I here assume to stand for an actual person who really is thinking. The sculpture depicts a nude male sitting on a rock, resting his chin on the back of his right hand and his right elbow on his left thigh. His posture and muscular tension in masterly fashion reflect the dialectical tensions of thinking, and Le Penseur is quickly recognized as a thinker. It is obvious that a thin description alone does not get far 
in describing his activity; the description would be largely exhausted by detailing his posture. Perhaps he is also engaged in further observable activities, like Euclid when thinking about geometry, whom Ryle imagines "muttering to himself a few geometrical words and phrases, or scrawling on paper or in the sand a few rough and fragmentary lines" (Ryle [1968] 2009, 510). Such activities may be part of thin description, but at this level, the description would still be largely incomplete. The reasons why, however, may not be immediately obvious. Could Le Penseur not be thinking solely propositionally and at the same time speaking aloud his every thought? Wouldn't his thinking then be capable of being captured by thin description?

Ryle would have two answers to this objection. The first is that a precise description of all pitches of the thinker's voice or a complete recording of them would no more get to the essence of his thinking than the videotape of the wink would get to the core of the winking. On its own, the recording would grasp the meaning of the recorded voice no more than a parrot speaking words it doesn't understand. To be sure, thin description can be much more than just a recording. It may use terms such as "holding his chin" or "sitting in a crouched position." These expressions go well beyond the phonetic level and make sense only to those who understand English. Yet by themselves they don't enable us to understand what he is doing apart from sitting in that position. If we were also to include the propositions he is speaking, however, we would need to be a little more specific. Thin description can include some understanding, for example, the observational meaning of the action of closing one's eyelid. If that's all the thinker is thinking about, and he says everything he is thinking about, then this content of his thinking could be accounted for by thin description.

Nevertheless, that wouldn't suffice for thinking, which brings us to Ryle's second answer. Thinking goes beyond its contents by relating them to each other and reflecting on them. Thinking aloud is different from verbally explaining something. The thinker does not yet know the outcome of his thinking; he is a "pioneer" (Ryle [1968] 2009, 509). He does not yet know the way, and if the way he takes leads to a quagmire, the least he can learn is which way not to take. Ryle contrasts this with an expert explaining an issue, knowing already what she is trying to explain; thinking about something is not like explaining something. While thinking is not the same as speaking, it can be enacted by speaking, such as when one freely develops a thought in language.

According to Ryle, the thinking of Le Penseur is taken to stand on a high reflective level. We may say that he is "trying, by success/failure tests, to find out whether or not the things that he is saying would or would not be utilisable as leads or pointers" ([1968] 2009, 508). This is a very thick description because it includes several layers of reflection. In other cases, thinking may be less reflective. We can say of a person playing tennis that she is thinking while playing (cf. Ryle [1967] 2009, 480). While concentrating on the game, her thinking guides and directly expresses itself in her actions; she may, for instance, anticipate the strategy of her opponent and counter it with what she thinks is the best move. Unlike the 
reflective thinking of Le Penseur, her thinking is immersed in her environment, at least with regard to the features relevant to her game. The point about thinking is not whether it is detached from its environment but how it deals with the things it is about. The things may be in the environment, such as Tetris figures on a screen, or merely imagined. Thinking manipulates them in intelligent and creative ways that combine, for example, the characteristics of the things, purposes, and possibilities of change.

On the one hand, in thinking we understand the significance of what we think about, which is sometimes rather thin and sometimes rather thick. On the other hand, thinking brings the objects of thought together in ways that accomplish new significance, which stands on yet thicker levels. If we understand thinking as something that can be done consciously, as I think we should, then consciousness accomplishes significance not only on relatively thin but also on very thick levels. The more or less thick levels of significance may furthermore influence each other. An example of thicker significance potentially influencing the thinner perception of pain is given by Henningsen and Sattel (this vol.). They point out that the existence in Japanese of the medical concept katakori (insufficiently translated as "neck and shoulder pain") actually makes Japanese people more prone to experience the condition than speakers of other languages. Likewise, thick conceptions such as "medicinal beliefs" and theories can become part of a culinary tradition that influences food preferences, which in turn alter that tradition (Jain, Rakhi, and Bagler 2015, 5).

\section{Thicker and Thinner Descriptions of Culture}

In contrast to the preference for thin definitions of consciousness in contemporary philosophy, the academic discourse on culture tends to define "culture" in very thick terms. Edward Tylor famously defined culture as "that complex whole which includes knowledge, belief, art, morals, law, custom and any other capabilities and habits acquired by man as a member of society" $(1871,1)$. Kroeber, Kluckhohn, and Untereiner (1952) compiled a list of more than 150 definitions, a meticulous work continued by Baldwin et al. ([2006] 2008), who analyzed about 300 definitions and categorized them under the seven headings of structure, function, process, product, refinement, group, and power or ideology.

I lack the space here to even list the titles of the plethora of definitions, but it is worth pointing out that while they show a tendency to define culture in terms of reflective capabilities and their results, everyday habits and ways of perception are often included as well. Section 3.2 gives a good reason why: more reflective forms of significance are embedded in cultural behavior. Culture thus concerns all forms of significance that are common to groups of people and inherited by social rather than genetic means. The description of culture does not always have to be very thick, and less-thick description is also important for investigating the relation between culture and significance. 


\subsection{Thicker Descriptions of Culture}

Clifford Geertz attempts to overcome the "theoretical diffusion" $(1973,6)$ in definitions of culture such as those of Kroeber, Kluckhohn, and Untereiner by defining culture in terms of thick description. In his seminal essay Thick Description: Toward an Interpretive Theory of Culture, Geertz defines anthropology as "an elaborate venture in, to borrow a notion from Gilbert Ryle, 'thick description'” (6). Geertz points out that the thin description of a behavior as "rapid contraction of his right eyelid" would not yet amount to a description of its cultural significance; "as a cultural category, [twitches] are as much nonwinks as winks are nontwitches" (7; italics in original). A twitch is not a twitch if it could be a wink, and distinguishing twitches from winks is decisive for the anthropological description of winking behavior.

Assuming that Geertz is right, we may still ask whether all thick descriptions of the customs of a foreign culture are equally thick, or whether it makes sense to distinguish between levels of thickness. The latter approach is suggested by Wittgenstein. He was an avid reader of James Frazer's classic text The Golden Bough: A Study of Magic and Religion ([1890] 2003). What Wittgenstein gained from his reading was not so much knowledge about practices of magic and religion at various times and in various cultures as insights into what can go wrong in studying them. Frazer's explanations of numerous dark and mysterious practices are as questionable as they are fascinating. For instance, Frazer explains the custom of the rain dance as a consequence of the superstition that the dance itself causes rain (last paragraph of chap. 4). When by chance it rains, this merely confirms the dancers in their superstition that their dance was the cause. Wittgenstein objects that it seems odd that "people don't realize earlier that sooner or later it's going to rain anyhow" (Wittgenstein 1993, 121). He thinks that Frazer's explanations are primitive, crude, and misleading. They are prone to make the "explained" behavior look more strange than understandable.

Wittgenstein makes an important distinction between two descriptions of a culture we know very little about. He asks us to distinguish between the superstitiousness of the belief described and the superstitiousness of the description. If we ascribe to the people of a culture the belief that their head will fall off when they have killed an enemy, we would describe a belief that one can arguably call superstitious. The description itself, however, would "contain nothing superstitious or magical in itself" (Wittgenstein 1993, 133). That the people really have the belief that their head falls off when they have killed an enemy seems unlikely, as it could be contradicted by experience in a relatively straightforward manner. If they really held that superstitious belief, however, we could describe it without recurring to superstitious beliefs.

Describing the beliefs of the people being studied in terms of "ghost" or "soul," by contrast, is likely to bring superstitions into the description: "I should like to say: nothing shows our kinship to those savages better than the fact that Frazer has on hand a word as familiar to himself and to us as 'ghost' or 'shade' in order to describe the views of these people" (Wittgenstein 1993, 133). The kinship may actually help in understanding the other culture, but 
in Frazer's examples, the kinship seems to be limited to his imagination of the other culture. Frazer gathered all his examples from the stories and reports of others, and we just don't know enough about the customs themselves to make good inferences about the beliefs of their practitioners. It is likely that what seems to be a profound belief behind the customs is in fact nothing but a projection of Frazer's or our own fantasies.

Wittgenstein's examples of "head" and "soul" show that it makes sense to distinguish between levels on which concepts are embedded in a framework of cultural behavior, beliefs, and knowledge. Even the concept of "head" is embedded in such a framework. There may be cultures that have a different concept of body parts or don't even have a concept of the body part "head." If the anthropologist and the native who points toward a rabbit and says "gavagai" share the same pointing behavior, "gavagai" can mean "rabbits, stages of rabbits, integral parts of rabbits, the rabbit fusion, and rabbithood" (Quine [1960] 2013, 51). It could even mean something like "there it goes" (Quine 1973, 44).

Furthermore, the ordinary concept of the physical object head relates to cultivations of the concept in religion and science. These develop the ordinary concept and embed it in further meaningful contexts, some of which may in turn become part of the ordinary concept. Ultimately, even the ordinary concept of "head" as a physical object is embedded in a rich cultural context, but that does not mean that the whole context of meaning is evoked in every use of the concept. With concepts such as "ghost," "spirit," or "soul," by contrast, it is much harder to find a description that does not use an intricate framework consisting of theory, worldview, superstition, religion, or other knowledge and belief that has to be described in very thick terms. Taking all description of a culture to be thick in the same sense erases an important difference between forms of behavior that are expressions of metaphysical, theological, or ideological beliefs and forms of behavior that do not directly depend on such beliefs. Culture is expressed not only in the former but also in the latter.

Of course, there are radical differences between Frazer and Geertz. Frazer believes in a developmental theory of knowledge from superstition through religion to his own secular "science," and his interpretations of the customs he is trying to explain are informed by such theories rather than careful observation. Geertz's anthropological work, by contrast, involves direct contact with his "informants" in other cultures; he reflects on his own presuppositions and tests and constantly revises his theories. Many of Wittgenstein's criticisms of Frazer's methodology would not apply to Geertz. Geertz would surely agree with Wittgenstein that interpreting rain dances and other customs as superstitions or stupidities is bad anthropology, at least if based only on secondhand reports. But his strong emphasis on the thickness of anthropological description is prone to lump together decisively different forms of interpretation and to miss the use of thinner description of a culture.

\subsection{Thinner Descriptions of Culture}

Geertz's claim that all cultural description is thick shows the need to interpret and think about interpretation when understanding cultures and has been groundbreaking for 
anthropology. From a philosophical perspective, however, it is embedded in a problematic constructivist framework. Since every description is thick, even the "data" of anthropology are supposed to be constructions: "What we call our data are really our own constructions of other people's constructions of what they and their compatriots are up to" (Geertz 1973, 9). Geertz's "constructions of constructions" definition of the data of anthropology is echoed in his concept of culture: "The culture of a people is an ensemble of texts, themselves ensembles, which the anthropologist strains to read over the shoulders of those to whom they properly belong" (452). If this were literally so, we would be in a similar situation to Frazer, who only has recourse to texts describing the customs. Since Geertz does engage in fieldwork and spends time conversing with the people of specific cultures, his expression "ensemble of texts" must actually be somewhat metaphorical, indicating that even the most basic forms of interaction are embedded in "webs of significance" (5). ${ }^{4}$ Yet one may wonder if restricting the concept of anthropological data to linguistic expressions suffices to describe what is going on in a culture.

There are things that don't make it into the words of a people, perhaps because the authors don't find them important enough, or find them too embarrassing, or perhaps don't even realize they exist. For instance, gender differences are often either unspoken or denied. Of course, such things are often expressed in written or oral speech. But trying to gather everything about a culture solely from what is said or written would disregard a lot of useful evidence, such as interactions between genders. Texts are further removed from ordinary behavior and experience. Living cultures, in contrast, allow observation of behavior, immersion in the culture, interaction beyond talking with the people of the culture, and the opportunity to study them in experimental settings. Geertz did use some of these important means for understanding; his actual way of doing ethnology is not in question here. The problem is his conception of culture as a text, a metaphor that neglects all of these ways of understanding. It thus makes sense that, as Laurence Kirmayer points out, anthropology has subsequently moved on from that metaphor, and "current medical anthropology emphasizes that culture is embodied as well as discursive" (this vol., sec. 1).

Differentiating between levels of thickness allows us to see the abundance of forms of cultural behavior that can be described relatively thinly before considering their relations to thicker concepts. These encompass not only less-thick concepts such as those of body parts, which are likely to be common to most or all cultures. One can also think of basic forms of behavior that vary considerably from culture to culture, for example, the rhythm and speed of life or bodily forms of interaction such as the frequency of touch and the distance that feels comfortable in personal communication. Basic forms of behavior may indirectly and sometimes directly be due to thick beliefs, but this is evidently not always the case. On their own, they don't have any more significance than the eye contraction that could signify

4. For Geertz's own reconsideration of the notion of culture as a text, see Geertz 1988. 
either a twitch or a wink. Nevertheless, they may turn out to be more important than Geertz suggests.

Geertz calls his definition of culture "semiotic" (1973, 5, 24, 29-30), but what he means by this term is relatively narrow. Semiotics comprise syntax and semantics as well as pragmatics. This is so because language needs to be understood in the context of its use. Seen this way, thin and thick description do not merely require an understanding of the syntax and semantics of the interpretations of behavior or events by informants but also imply an understanding of the ways behavior gives meaning to the language of the culture and the interpretations by the members of the culture.

In contrast to Geertz's definition, Wittgenstein's writings express an extreme awareness of the role of behavior and interaction for significance. One can always define words with the help of other words, but significance goes beyond the relations of words to each other. Phonemes and symbols have no significance by themselves, but only when used in regular ways; without at least some regularity, language games would lose their point (cf. Wittgenstein [1953] 1997, §142). The regular uses of language can be quite specific, but Wittgenstein thinks that one can dig deeper and find a common ground beneath specific uses. The ground is not unquestionable or given once and for all; it may be more like a riverbed that changes much more slowly than the water running over it (cf. Wittgenstein 1997, §§96-99). As such a ground, it is likely to be common to all or most cultures. Wittgenstein writes that "the common behavior of mankind is the system of reference, with which we interpret a foreign language" (\$206). The latter may be universal to all humans, but Wittgenstein's expression "mankind" should not be overstated (cf. Schulte 1990, 157); forms of behavior may be common to only certain groups of people (Durt 2005, 62-64). Such groups of people are cultures or subcultures; cultural behavior accomplishes significance.

Much of the "common behavior of mankind" may be described in relatively thin terms. However, I interpret Wittgenstein to mean that this is not always the case and that at least some of this common behavior needs to be described thickly. The history of the use of the concept of behavior in theories such as behaviorism makes the concept prone to be misunderstood as something that can always be described thinly. Behaviorism assumed a highly reductive concept of behavior, which often meant little more than bodily motion. But, to the contrary, behavior is often extremely complex, such as in the case of reflective thinking, and has to be described thickly. The more the behavior is interwoven with particular beliefs and ways of thinking, the more likely it is to be specific to groups smaller than the whole of humankind.

Together with the beliefs and ways of thinking with which behavior is interwoven, the thinner behaviors common to a culture provide a system of reference. Culture accomplishes significance through both specific and more common forms of behavior. This is the fundamental reason why Geertz's metaphor of text is insufficient: texts cannot be understood without understanding the underlying forms of behavior. 


\section{Embodied Accomplishments and the Integrative Nature of Consciousness}

Behavior is an important topic for the study of embodiment because all behavior is embodied. But talk of different levels of accomplishment of significance may raise the question of whether they involve different kinds of embodiment. I argue that the categorical difference exists not between different levels of embodied accomplishment but between different levels of significance. Even very thick accomplishments such as thinking build on preconscious accomplishments as well as lower levels of significance. Consciousness is embodied at all levels of accomplishment, integrating different levels of significance.

\subsection{Embodied Accomplishments and Accomplishments of the Body}

Like Wittgenstein, Ryle sometimes thinks of behavior as being thick, as is obvious from the fact that he views even thinking as a form of behavior (cf. Ryle [1940] 2009, 197); behavior comprises externally observable thin behavior as much as complex forms of behavior. As forms of behavior, all levels of accomplishing activity are embodied. The higher levels of accomplishing activity build in turn on lower levels, preserving their embodied accomplishments.

Conscious accomplishments, such as the conscious recognition of a wink, build on preconscious accomplishments. We usually become aware of the wink immediately, without having to go through a conscious process of interpreting the contraction of the eyelid. Ryle does not undertake an analysis of the different accomplishments entailed in perception, but other philosophers have done so. Edmund Husserl, for instance, distinguishes between "passive" and "active synthesis," both of which disclose the significance of the intentional objects of consciousness. Passive synthesis concerns the subjective and intersubjective processes that prereflectively accomplish the constitution of the intentional objects, while active synthesis concerns more reflective accomplishments such as judgments (cf. Husserl 1966). One may furthermore attempt to go beneath experience altogether and try to determine the roots of significance in the biological activity of organisms. In Varela's interpretation, the activity of bacteria in swimming toward parts of a solution with a higher sugar gradient can be described as "food significance" (Varela 1991, 87); the bacteria make sense of their environment by interacting with it in meaningful ways. One may question whether biological significance is still the same kind of significance, but even if not, this would be no reason to deny that there are bodily accomplishments that go beneath consciousness and on which conscious accomplishments can build.

But how much can we explain by describing the unconscious activities going on in the body? For instance, in the act of thinking, the externally visible movements of the thinker's body play only a minor role. But beneath these externally visible movements we find a profusion of bodily goings-on. Suppose that it was practical to look at all the processes within the thinker's body, in particular his brain. To describe the brain processes, we can imagine either a thin or a thick description. 
It is often assumed that the thinker's brain processes can be described in rather thin terms. One may naively imagine small wires connecting nodes and think of electric charges moving like lights between them. Such a description would not be on the same level as the description of the contraction of the eyelid of the twitcher or winker, but it may be close enough to call it "thin description." If such a thin description were possible, however, the described processes would clearly not be on the level of accomplishment of thick description, and no number of such descriptions, taken by themselves, could remedy this. Thick description is about a level of significance not entailed in thin description and is thus not reducible to thin description.

In fact, however, brain science gives a much thicker description of the brain. Scientific description generally has to do with conceptualizing and interpreting data by means of hypothetical assumptions and theories, and is in this regard always thick. But even in this regard, a thick description of brain processes alone would not amount to a thick description of the thinking process because, by itself, it would not relate these brain processes to the levels of accomplishment pertinent to thinking. The description of thinking not only has to be thick but also has to be thick in the right way. Its study would have to include the levels of accomplishments of the particular act of thinking, but that would be a science very different from today's brain science and maybe closer to today's human sciences.

In other words, we can coherently say that the thinker is thinking by using his brain, or even that he is thinking with his brain. But that does not mean that his thinking is in his brain, because the description of the brain by itself would not include the relations between the levels of accomplishments involved in thinking. Rather than being a place of thinking, the human brain is a "relational organ" that is not only part of an organism but also embedded in wider contexts, including those of cultural significance (cf. Fuchs 2008, 217).

It would be a misunderstanding to conceive these relations independently of bodily experience. The embodied being is more than a physical body. It is a body that is physical and at the same time experienced as a sensible body. Furthermore, it is experienced as a body that can initiate or control a range of movements. We may say that the embodied being is a living body or, with Husserl, that it is a Leib ([1913] 1976, 116). I think that as soon as there is an experience of one's body as a Leib, we can speak of a conscious being. Reflective consciousness is not required, and contra Descartes, animals experience their body as a Leib and thus have consciousness. Nevertheless, as I argued earlier, human consciousness also encompasses reflective levels of significance. The next section delineates the idea that embodiment of consciousness contributes to the integration of different levels of significance.

\subsection{The Integrative Nature of Embodied Consciousness}

The distinction between different levels of significance may sound to some like a hybrid concept of the human mind. Merlin Donald argues for such a view and claims that the human mind is torn between two modes: 
We have hybrid minds. Like the monsters of Greek mythology, we are two creatures struggling within a single body. We are capable of operating within that same fuzzy analogue mode that constituted the whole of the cognitive universe for our ancestors, while another part of us operates like the symbolic machines we have made. But mostly we muddle through with various patched-together hybridized modes of thinking and feeling. Our conscious experience reflects this. These two sides of our being are engaged in a constant struggle of ownership or awareness. (Donald 2001, 164)

In this citation, Donald draws not only on ancient mythology but also on ancient Greek conceptions of competing parts of the soul, such as Plato's tripartite concept of the soul in his chariot allegory (Plato 1903, 246a-254e). Donald simplifies and modernizes the ancient conceptions with his claim that there are two competing parts of the human mind: the "analogue" and "symbolic" mode. This does not really contradict the notion of embodiment, though, since symbolic machines are material and could become part of a body, for example, by implanting a computer in someone's brain. But we are not cyborgs yet, and we have no neuroscientific evidence for a symbol-processing system separate from the "analogue" neuronal processes in the human nervous system. As with Donald's interpretation, the claim criticized by Di Paolo and De Jaegher (this vol.) that embodiment can only explain "direct action-based mechanisms" while "more reflective tasks" are disembodied makes little sense.

Donald's metaphoric claim makes more sense if we understand it to mean a categorical distinction not between different parts of the body but between different kinds of significance. With regard to significance, one can indeed draw a categorical distinction between "analogue" and "symbolic." On the one hand, generalizations comprise essential features of concretely experienced objects and may be called "analogue" because they are always vague or "fuzzy." On the other hand, idealizations and formalizations are limit objects that can be manipulated by syntactic operations (cf. Durt 2012, 164). This is the working mode of our "symbolic machines." Generalizations can be experienced, while idealizations and formalizations cannot be experienced in themselves, although they are accomplished by operations on experienceable objects such as measurement techniques (145-166).

Ryle's distinction between levels of accomplishment offers one way of understanding how higher levels of significance build on lower levels, preserving the embodied accomplishments of the lower levels and giving rise to new embodied accomplishments. Often the implied accomplishments are difficult to bring to light because they have developed over generations in cultural processes. Besides the symbolization techniques at the core of symbolic language, humans have mastered a large number of techniques that accomplish significance far beyond concrete experience. An important example is the ability to deal with ideal objects. Numbers are abstracted from concrete experience via techniques of idealization, which are then further developed by formalization techniques, allowing for new kinds of significance. Such techniques are cultural not in that they could exist in only one culture but in that they derive from specific forms of behavior that are intertwined with cultural systems of knowledge and belief. As techniques, they are just as embodied as any cultural forms of behavior. 
These considerations tell against Donald's claim that the two modes of the human mind are opposed and in struggle. Of course, everything that grasps our attention has to prevail against other things that simultaneously demand our attention. But when this is experienced as a constant struggle and insurmountable conflict between two monsters, creatures, or actors in one consciousness, we come close to a psychopathological case. Dissociative identity or multiple personality disorder may be an obvious example, but one may also think of forms of "schizophrenic alienation" (schizophrene Alienation; Blankenburg 1971, 9). Patients with this condition suffer from what Sass calls "hyperreflexivity" $(2001,259)$; they feel the need to constantly reflect on even the most mundane actions, which can prevent them from doing those very things.

In healthy persons, by contrast, more or less reflective forms are combined in productive ways that allow the person to act coherently. Of course, there are also conflicts in the consciousness of healthy beings between different levels of reflection. But in this chapter I have given reasons for that these levels are not intrinsically contradictory and rather build on each other. To conclude, let us consider an example of a conscious activity of a healthy person that suggests that consciousness unites perception and movement into a kinesthetic system.

Consider a person who is psychologically and physiologically in good shape learning to perform a handstand. While practicing, she will suppress thoughts about dinner in favor of concentrating on holding her feet in the air. Some of that suppression will already be done subconsciously, and later, when she is able to do the handstand "automatically," she will be able to think about her dinner at the same time. But while she is learning, she needs to focus on the right things on pain of falling. She may have a teacher giving her verbal instructions such as "activate your core," "clasp the floor with your fingers," "look in front of your hands," "move your hip up as high as possible," and "carefully raise your feet." But such propositions are only scaffolds she is learning to apply in the right way. Ultimately she will be able to do the handstand without them. For now, they (hopefully) help her guide her actions.

This is so because she knows or learns their significance for her action and knows or learns how to combine them into one action. Consciousness integrates thinner and thicker forms of significance in experience, reflection, understanding, desire, and action. This integrative nature is what Merleau-Ponty calls the "intentional arc" (cf. Tewes, Durt, and Fuchs, introduction to this vol.). That consciousness is embodied is not a hindrance to integration but rather enforces the integration of different streams that otherwise may veer off indefinitely. In the case of the learner of a difficult practice, there is simply no time for consciousness to wander off.

These considerations are more compatible with the ancient chariot allegory than with Donald's concept of the digital and analogue parts of the mind. In contrast to Donald's concept, the chariot allegory had a placeholder for the integrative nature of consciousness, namely, the charioteer. As said, part of the integration of levels of significance is done subconsciously or automatically, and consciousness only controls the performance. But, as in the case of the learner, other parts will have to be done by conscious effort. Rather than being 
a mere passive stream of subjective experience, consciousness actively integrates the various experiences, thoughts, desires, and actions. The "stream of consciousness" or "stream of thought" (James [1890] 1918, 224-290; Husserl 1973, 171-191) can itself be guided by consciousness. Consciousness always has a character of mineness (cf. Zahavi 2014, 19), and already here we may be able to speak of a "self." Even with respect to thin self-experience in this sense, one may distinguish between the sense of ownership and the sense of agency and ask whether the minimal self includes a sense of agency (cf. Gallagher 2000). Agency in connection with thicker levels of significance, such as in thinking, is another important topic that has to be left to future investigation. For now, I hope it has become plausible that culture, consciousness, and significance are intrinsically intertwined, and that their relation is important for the investigation of each of the three.

\section{Conclusion}

Going beyond the common restriction of consciousness to phenomenal experience, this chapter has contended that, on the one hand, consciousness discloses aspects of significance in experience and understanding. Culture, on the other hand, systematically comprises shared significance and accomplishes significance through shared forms of behavior. Consciousness discloses aspects of the significance that is established and expressed in cultural behavior. Cultural behavior, in turn, builds on conscious experience and understanding and is guided by consciousness. Consciousness and culture are closely interdependent through their accomplishment of significance.

\section{Acknowledgments}

Many thanks to Christian Tewes, Christian Spahn, Thomas Fuchs, Aloisia Moser, Anita Galuschek, Tilman Staemmler, and Ruiming Zhang for their insightful and inspiring comments on drafts of this chapter. Work on this chapter was supported by the DFG excellence initiative Cultural Dynamics in Globalised Worlds and by the European Union's Horizon 2020 research and innovation program under the Marie Skłodowska-Curie Individual Fellowship no. 701584 .

\section{References}

Baldwin, J., S. L. Faulkner, M. L. Hecht, and S. L. Lindsley, eds. [2006] 2008. Redefining Culture: Perspectives across the Disciplines. Taylor \& Francis e-Library.

Blankenburg, W. 1971. Der Verlust der Natürlichen Selbstverständlichkeit: Ein Beitrag zur Psychopathologie Symptomarmer Schizophrenien. Ferdinand Enke.

Chalmers, D. 1995. Facing up to the problem of consciousness. Journal of Consciousness Studies 2 (3): 200-219. 
Crane, T. 2013. The Objects of Thought. Oxford University Press.

Descartes, R. [1637] 1902. Discours de la méthode pour bien conduire sa raison, et chercher la vérité dans les sciences. In Evres de Descartes: Discours de la méthode \& essais VI, ed. C. Adam and P. Tannery. Librairie Philosophique J. Vrin.

Donald, M. 2001. A Mind So Rare: The Evolution of Human Consciousness. Norton.

Durt, C. 2005. Wittgensteins interkulturelle Perspektive: Auf der Suche nach gemeinsamen Handlungsweisen. In Wahr oder Tolerant: Religiöse Sprachspiele und die Problematik ihrer globalen Koexistenz, Wittgenstein-Studien 11, ed. W. Lütterfelds, T. Mohrs, and D. Salehi, 57-76. Peter Lang.

Durt, C. 2012. The paradox of the primary-secondary quality distinction and Husserl's genealogy of the mathematization of nature. PhD diss., University of California at Santa Cruz. http://www.durt.de/diss/ Paradox.html.

Frazer, J. G. [1890] 2003. The Golden Bough: A Study of Magic and Religion. Project Gutenberg eBook. https://www.gutenberg.org/files/3623/3623-h/3623-h.htm (accessed August 30, 2004).

Frege, G. [1918] 2003. Der Gedanke: Eine logische Untersuchung. In Logische Untersuchungen, ed. G. Patzig, 35-62. Vandenhoek \& Ruprecht.

Fuchs, T. 2008. Das Gehirn-Ein Beziehungsorgan: Eine phänomenologisch-ökologische Konzeption. Kohlhammer.

Gallagher, S. 2000. Philosophical conceptions of the self: Implications for cognitive science. Trends in Cognitive Sciences 4 (1): 14-21.

Geertz, C. 1973. The Interpretation of Cultures. Basic Books.

Geertz, C. 1988. Works and Lives: The Anthropologist as Author. Stanford University Press.

Hacker, P. 2002. Is there anything it is like to be a bat? Philosophy 2 (4): 157-174. doi:10.1017/ S0031819102000220.

Husserl, E. [1913] 1976. Ideen zu einer reinen Phänomenologie und phänomenologischen Philosophie. Erstes Buch: Allgemeine Einführung in die reine Phänomenologie 1. Halbband: Text der 1-3 Auflage. Husserliana III/1. Ed. K. Schuhmann. Martinus Nijhoff.

Husserl, E. 1962. Die Krisis der europäischen Wissenschaften und die transzendentale Phänomenologie: Eine Einleitung in die phänomenologische Philosophie. Husserliana VI. Ed. W. Biemel. Martinus Nijhoff.

Husserl, E. 1966. Analysen zur passiven Synthesis: Aus Vorlesungs- und Forschungsmanuskripten, 1918-1926. Husserliana XI. Ed. M. Fleischer. Martinus Nijhoff.

Husserl, E. 1973. Zur Phänomenologie der Intersubjektivität: Texte aus dem Nachlass Erster Teil, 1905-1920. Husserliana XIII. Ed. I. Kern. Martinus Nijhoff.

Inkpin, A. 2016. Disclosing the World: On the Phenomenology of Language. MIT Press. 
Jain, A., N. Rakhi, and G. Bagler. 2015. Spices form the basics of food pairing in Indian cuisine. Physics and Society. arXiv:1502.03815v1 (accessed January 2, 2016), 1-30.

James, W. [1890] 1918. The Principles of Psychology. Dover.

Kroeber, A., C. Kluckhohn, and W. Untereiner. 1952. Culture: A Critical Review of Concepts and Definitions. Peabody Museum of American Archaeology and Ethnology.

Locke, J. [1689] 1836. An Essay Concerning Human Understanding. Tegg.

McDowell, J. [1994] 2002. The content of perceptual experience. In Vision and Mind: Selected Readings in the Philosophy of Perception, ed. A. Noë and E. Thompson, 443-458. MIT Press.

Nagel, T. 1974. What is it like to be a bat? Philosophical Review 83 (4): 435-450.

Plato. 1903. Phaedrus. In Platonis Opera, ed. J. Burnet. Oxford University Press. http://data.perseus.org/ texts/urn:cts:greekLit:tlg0059.tlg012 (accessed March 12, 2015).

Quine, W. [1960] 2013. Word and Object. MIT Press.

Quine, W. 1973. The Roots of Reference. Open Court.

Ratcliffe, M. 2014. Some Husserlian reflections on the contents of experience. In Philosophical Methodology: The Armchair or the Laboratory? ed. M. Haug, 354-378. Routledge.

Rosenthal, D. 2004. Varieties of higher-order theory. In Higher-Order Theories of Consciousness: An Anthology, ed. R. Gennaro, 17-44. John Benjamins.

Ryle, G. [1940] 2009. Conscience and moral convictions. In Collected Essays, 1929-1968: Collected Papers, vol. 2, 194-202. Routledge.

Ryle, G. [1967] 2009. Thinking and reflecting. In Collected Essays, 1929-1968: Collected Papers, vol. 2, 479-493. Routledge.

Ryle, G. [1968] 2009. The thinking of thoughts: What is "Le Penseur" doing? In Collected Essays, 19291968: Collected Papers, vol. 2, 494-510. Routledge.

Sass, L. 2001. Self and world in schizophrenia: Three classic approaches. Philosophy, Psychiatry, and Psychology 8 (4): 251-270.

Searle, J. 2000. Consciousness. Annual Review of Neuroscience 23:557-578. doi:10.1146/annurev .neuro.23.1.557.

Schulte, J. 1990. Chor und Gesetz: Wittgenstein im Kontext. Suhrkamp.

Shoemaker, S. 1990. Qualities and qualia: What's in the mind? Philosophy and Phenomenological Research 50 (4): 109-131.

Strawson, G. [1994] 2010. Mental Reality. 2nd ed. MIT Press.

Throop, J., and C. Laughlin. 2007. Anthropology of consciousness. In The Cambridge Handbook of Consciousness, ed. E. Thompson, 631-669. Cambridge University Press. 
Tylor, E. 1871. Primitive Culture: Researches into the Development of Mythology, Philosophy, Religion, Art, and Custom. Vol. 1. John Murray.

Varela, F. 1991. Organism: A meshwork of selfless selves. In Organism and the Origin of Self, ed. A. Tauber, 79-107. Kluwer Academic.

Wittgenstein, L. 1993. Bemerkungen über Frazer's Golden Bough: Remarks on Frazer's Golden Bough. In Philosophical Occasions, 1912-1951, ed. J. Klagge and A. Nordmann, 118-155. Hackett.

Wittgenstein, L. [1953] 1997. Philosophical Investigations. Blackwell.

Wittgenstein, L. 1997. Über Gewissheit. Suhrkamp.

Zahavi, D. 2014. Self and Other: Exploring Subjectivity, Empathy, and Shame. Oxford University Press. 